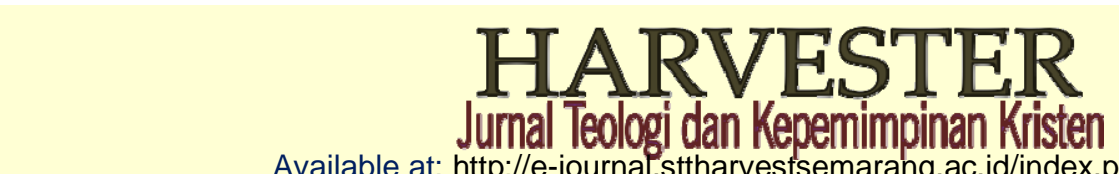

Available at: http://e-journal.sttharvestsemarahg.ac.id/index.php/harvester

Volume 5,No2, Desember 2020;(120-134)

e-ISSN2685-0834,p-ISSN2302-9498

\title{
Penginjilan Sebagai Upaya Meneguhkan Keyakinan Keselamatan Anak
}

\author{
Kristian Badai \\ Sekolah Tinggi Agama Kristen Terpadu Pesat Salatiga \\ e-mail: christianbaday017@gmail.com \\ Kaleb Djeremod \\ Sekolah Tinggi Agama Kristen Terpadu Pesat Salatiga \\ e-mail: kalebdieremod@gmail.com \\ Frets Keriapy \\ Sekolah Tinggi Agama Kristen Terpadu Pesat Salatiga \\ e-mail:fretskeriapv1106@gmail.com
}

\begin{abstract}
This objective is to describe how the process of affirming a child's faith to be more firm in Jesus Christ, even though there are other beliefs around the child, even the child's intellect is attacked by the internet, research at school or the environment. The title of this scientific paper is evangelism as an effort to strengthen the belief in the safety of children aged 13-16 years at the Future Center Sion Tridamarsari. The assurance of salvation in Jesus needs to be strengthened, especially in Christian children. Confirming the safety of children in Jesus is done through evangelism. Because through evangelism, children will realize that salvation is only in Jesus. In addition, children can experience an authentic encounter with God through the mediation of the Holy Spirit. Christian children at the Future Center Sion Tridamarsari, especially those aged 13-16 years who need to be evangelized, then what are the ways to convey the gospel to children. This study uses qualitative research methods and the informants in this study were nine children. Interview method. The results of the study found that three children who believed were saved in Jesus with an understanding because they believed Jesus had saved, while the other six believed they were saved because they did spiritual activities. This can provide evidence that most children have not seen clear reasons why believing in Jesus and Jesus guarantees salvation for every believer because the tutors have not maximized evangelism to children, so that it has not had an impact on confirming the belief in child safety.
\end{abstract}

Keywords: Evangelism, Confirming, Salvation Confidence

Abstrak: Tujuan penelitian ini adalah mendeskripsikan bagaimana proses meneguhkan iman anak agar semakin teguh dalam Yesus Kristus, walaupun sekeliling anak terdapat kepercayaan lain, bahkan diserangnya intelek anak oleh internet, pengajaran disekolah atau lingkungan. Judul karya ilmiah ini adalah penginjilan sebagai upaya meneguhkan 
keyakinan keselamatan anak usia 13-16 tahun di Future Center Sion Tridamarsari. Keyakinan keselamatan pada Yesus perlu diteguhkan, khususnya pada anak-anak yang beragama Kristen. Meneguhkan keyakinan keselamatan anak pada Yesus dilakukan melalui penginjilan. Karena melalui penginjilan, anak akan menyadari dengan pasti bahwa keselamatan hanya ada dalam Yesus. Selain itu anak dapat mengalami perjumpaan yang autentik dengan Tuhan melalui perantaraan Roh Kudus. Anak Kristen yang ada di Future Center Sion Tridamarsari, khususnya usia 13-16 tahun perlu diinjili. Penelitian ini menggunakan metode penelitian kualitatif dan informan dalam penelitian ini adalah sembilan anak. Metode pengumpulan data menggunakan wawancara. Hasil penelitian menemukan bahwa, tiga anak yang yakin diselamatkan dalam Yesus dengan pemahaman karena percaya Yesus telah menyelamatkan sedangkan enam lainnya yakin diselamatkan karena melakukan kegiatan kerohanian. Hal tersebut dapat memberi bukti bahwa sebagian besar anak-anak belum mengetahui alasan jelas mengenai kenapa harus percaya pada Yesus dan Yesus jaminan keselamatan bagi setiap orang percaya karena para tutor belum memaksimalkan penginjilan pada anak, sehingga belum memberi dampak untuk meneguhkan keyakinan keselamatan anak.

Kata kunci: Penginjilan, Meneguhkan, Keyakinan Keselamatan

\section{PENDAHULUAN}

Keselamatan yang diperoleh oleh setiap manusia percaya adalah karena adanya pengorbanan Yesus Kristus di kayu salib. Artinya keselamatan bukan karena usaha atau perbuatan baik, namun karena kasih Allah terhadap manusia (Efesus 2:8-9). Ketika seseorang telah menerima keselamatan dalam Kristus, yang berarti mengakui Yesus sebagai Tuhan dan Juruselamat, ia dijadikan sebagai ciptaan baru (2 Kor. 5:17). Kemudian, setiap orang yang menerima Yesus diberi kuasa agar menjadi anak-anak Allah (Yoh. 1:12), sehingga orang percaya memiliki hubungan sebagai anak dan Bapa di dalam Kristus. Dengan demikian, keselamatan yang telah diperoleh secara cuma-cuma, haruslah juga disampaikan kepada orang yang belum percaya pada Yesus, agar mereka juga dapat diselamatkan. Karena semua orang pada dasrnya ingin diselamatkan. Hal inilah yang menjadi tugas orang percaya yang telah diselamatkan. Hal tersebut pula yang telah diperintahkan Yesus sebelum Ia naik ke sorga dalam Matius 28:19-20, atau Kisah Para Rasul 1:8. Sehingga perintah tersebut dalam kekristenan dikenal dengan sebutan Amanat Agung 1 .

Perintah tersebut juga dikenal dengan penginjilan. Penginjilan merupakan suatu keharusan bagi setiap orang yang percaya untuk memberitakan Yesus pada orang lain. Karena Paulus telah menegaskan dalam 1 Kor. 9:16, bahwa penginjilan merupakan sebuah

\footnotetext{
${ }^{1}$ Djuwansah Suhendro P Stephanus, "Mengajarkan Penginjilan Sebagai Gaya Hidup Orang Percaya," REDOMINATE: Jurnal Teologi dan Pendidikan Kristiani 1, no. 1 (2019): 12-22.
} 
keharusan. Karena seseorang yang datang membawa kabar baik tentang Yesus Kristus merupakan suatu Anugerah dari Allah. Hal inilah yang dimaksudkan dalam Roma 10:14-15, bahwa orang percaya merupakan pelaku utama dalam penginjilan atau pemberitaan kabar baik.

Yakob Tomatala mendefinisikan penginjilan sebagai bagian utuh dari rencana misi Allah yang bertujuan membawa Shalom kepada manusia dan seluruh ciptaan-Nya."2 Untuk melaksanakan rencana misi-Nya, Allah telah memberikan "Mandat Misi" bagi umat-Nya untuk menjadi mandataris-Nya. Sebagai mandataris Allah, umat Tuhan diberikan tanggung jawab untuk memenuhi bumi dengan umat-Nya serta menaklukkan dan menguasai bumi bagi kemuliaan-Nya (Kej. 1:28). Pada saat manusia jatuh ke dalam dosa (Kej. pasal 2 dan 3), Allah memberikan "Janji penyelamatan atau kabar baik Injil“" yang paling awal dengan suatu tujuan membebaskan manusia dari dosa (Kej. 3:15, Gal. 4:4, Mat. 1:21, 1 Tim. 2:5). ${ }^{3}$

Dengan demikian penginjilan adalah sesuatu yang dikatakan dan dikerjakan. Salah satu lembaga yang berperan dalam penginjilan adalah gereja. Gereja adalah orang-orang yang dipanggil dari kegelapan menuju terang Allah yang ajaib. Amanat Agung berlaku bagi semua orang termasuk anak-anak. Anak-anak lebih dari kelompok manusia manapun juga. Anak-anak adalah orang-orang yang reseptif terhadap injil. Oleh karena itu, pemberitaan injil yang lebih efektif ketika dimulai dari anak-anak, karena masa anak-anak adalah masa belajar yang paling efektif, termasuk dalam hal keyakinan keselamatan kepada Yesus Kristus. Anak-anak membutuhkan perjumpaan yang autentik dengan Kristus supaya mengalami kepenuhan hidup yang disediakan Allah bagi anak-anak. Dalam Alkitab, Injil harus diberitakan kepada semua orang, termasuk anak-anak dengan maksud dan harapan menjadi pengikut Kristus. Oleh sebab itu penginjilan tidak hanya berfokus pada sekelompok manusia dewasa saja, namun penginjilan harus disampaikan secara menyeluruh bagi semua orang termasuk anak-anak. Hal ini menunjukkan bahwa penginjilan yang dilakukan adalah penginjilan yang Alkitabiah ${ }^{4}$. Allah tidak menghendaki supaya seorangpun dari anak-anak hilang 5 .

Penginjilan sangat penting disampaikan, supaya semua orang termasuk anak-anak dapat diselamatkan melalui pengorbanan Yesus Kristus yang mati di kayu salib. Dalam kehidupan yang dimulai pada Perjanjian Baru hingga dunia modern saat ini, bahwa hanya

\footnotetext{
${ }^{2}$ Y. Tomatala, Penginjilan Masa Kini Jilid 2 (Malang: Gandum Mas, 2004), 7.

${ }^{3}$ Y. Tomatala, Penginjilan Masa Kini Jilid 2.

${ }^{4}$ Sam Doherty, Mengapa Menginjili Anak-Anak (Indonesia, 2002), 12.

5 Adelaide F. Heath, Strategi Membimbing Anak Hidup Dalam Kristus (Bandung: Kalam Al-Hayat, 2013), 61 .
} 
HARVESTER: Jurnal Teologi dan Kepemimpinan Kristen, Vol 5, No 2, (Desember 2020)

melalui pengorbanan Yesus Kristus setiap dosa manusia dapat ditebus dan diselamatkan dalam kehidupan kekal (Surga). Keselamatan bukanlah sesuatu yang dimiliki seseorang atau suatu organisasi dan kemudian disampaikan kepada orang lain, melainkan sesuatu yang tercipta karena terjadi perubahan keadaan. Jadi dalam keselamatan tidak ada dalam diri seseorang melainkan keselamatan itu diberi dalam suatu keadaan kepada manusia yang berdosa karena tanpa keselamatan kehidupan manusia akan hancur dan hubungan antara Allah dengan manusia akan hilang, jadi keselamatan itu sangat penting bagi umat manusia. ${ }^{6}$ Jika dalam lingkungan anak-anak tidak semua beragama Kristen, maka penginjilan perlu disampaikan, agar anak memahami dengan pasti makna Injil.

Meneguhkan keyakinan atau kepastian keselamatan anak Future Center dalam Yesus Kristus melalui penginjilan bertujuan untuk menolong anak dalam iman percaya yang teguh, menyadari bahwa keselamatan hanya ada dalam Yesus dan memiliki konsep berpikir tentang Yesus yang dipercayai. Membimbing anak merupakan strategi yang dapat dilakukan untuk menolong anak bertumbuh dalam Yesus Kristus yang dipercayai. Membimbing anak mengenal Kristus merupakan suatu upaya melengkapi kemampuan intelektual anak agar dapat berpikir sebagai orang Kristen yang memiliki Worldview Christian (pandangan Kristen terhadap pikiran dunia) ${ }^{7}$.

Melengkapi intelektual anak tentang Yesus merupakan suatu upaya yang baik dilakukan oleh pembimbing atau pengajar di Future Center Sion Tridamarsari 13-16 tahun, sehingga pada masa pertumbuhan anak dapat mempertahankan iman percaya pada Yesus dengan teguh sampai akhir hidupnya. Walaupun berada pada keberagaman ideologi dalam lingkungan anak-anak, jika dengan adanya pemahaman mengenai keyakinan keselamatan yang baik dalam diri anak, maka anak juga dapat menjadi pelaku pemberita kabar baik bagi orang lain.

Keberagaman kepercayaan dapat menjadi pemicu yang melemahkan keyakinan keselamatan anak sehingga dapat menjadikan iman anak menjadi tidak teguh. Selain itu, di tempat belajar pun seperti di sekolah, banyak keberagaman yang bisa ditemukan. ${ }^{8}$ Selain itu, sekolah pun menjadi tempat untuk mengenalkan Kristus dalam kehidupan para nara didik. ${ }^{9}$

\footnotetext{
${ }^{6}$ Fredy Fredy, “Ajaran Tentang Keselamatan Dalam Kitab Injil Yohanes” (2018).

${ }^{7}$ Adelaide F. Heath, Strategi Membimbing Anak Hidup Dalam Kristus.

${ }^{8}$ Frets Keriapy, "Pendidikan Kristiani Transformatif Berbasis Multikultural Dalam Konteks Indonesia," REGULA FIDEI: Jurnal Pendidikan Agama Kristen 5, no. 2 (2020): 82-93.

${ }^{9}$ Romini Romini and Ida Destariana Harefa, "MANFAAT PENGGUNAAN ALKITAB BERGAMBAR TERHADAP PERKEMBANGAN KEROHANIAN ANAK FUTURE CENTER USIA 7-9 TAHUN DI BULUH AWAR," EDULEAD: Journal of Christian Education and Leadership 1, no. 1 (2020): 1-14.

Copyright@ 2020; HARVESTER; e-ISSN 2685-0834, p-ISSN 2302-9498 I 123
} 
Selanjutnya Yesus harus menjadi teladan hidup setiap umat yang percaya kepadanya. ${ }^{10} \mathrm{Hal}$ ini tidak hanya bisa dilakukan di sekolah, di rumah pun menjadi tempat bagi anak untuk dapat bertumbuh baik secara fisik maupun secara spiritual. ${ }^{11}$

Hal lain yang menjadi pemicu melemahnya keyakinan anak adalah "diserangnya" intelek anak dengan sengaja atau tidak oleh dunia internet maupun ajaran resmi di sekolah dan pengaruh lingkungan yang tidak percaya kepada Kristus. ${ }^{12}$ Kemudian anak-anak dapat menonton bermacam film yang memberi konsep moral dan konsep diri serta konsep rohani yang bertentangan dengan kebenaran Alkitab sehingga dapat mempengaruhi pikiran anak. Hal tersebut memberikan arti bahwa pikiran sekuler menentang atau melawan pikiran Kristen (Efesus 4:23). ${ }^{13}$ Contohnya saat ini banyak sekali terjadi kasus terkait pencemaran nama baik, penghinaan, prostitusi, penculikan, bullying yang dapat memicu depresi pada anak dan remaja. Kemudahan penyebaran informasi baik yang positif maupun negatif hingga seluruh dunia dan diketahuioleh pengguna media sosial membuat anak dan remaja malu, rendah diri, dan skit hati. Fenomena-fenomena ini menunjukkan penggunaan internet di Indonesia belum paham untuk menggunakan internet dengan baik dan benar. Di satu sisi mereka dapat mengakses jaringan, namun belum memahami seutuhnya konsekuensi penggunaan media digital. Jadi, walaupun telah menguasai baca tulis, namun pengguna internet di Indonesia belum sepenuhnya memiliki kemampuan literasi digital ${ }^{14}$.

Dengan demikian tutor harus memiliki empati dalam melakukan penginjilan yang dapat memberikan kontribusi dalam menolong meneguhkan keyakinan keselamatan anak Future Center Sion Tridamarsari usia 13-16 tahun untuk semakin teguh dalam iman percaya pada Yesus serta memiliki kemampuan untuk bertumbuh berkarakter seperti Kristus. Melihat identifikasi masalah di atas, maka peneliti tertarik untuk meneliti anak Future Center Sion Tridamarsari usia 13-16 tahun mengenai keyakinan keselamatan yang teguh dalam Yesus dengan judul; "Penginjilan Sebagai Upaya Meneguhkan Keyakinan Keselamatan Anak Usia 13-16 Tahun Di Future Center Sion Tridamarsari”.

${ }^{10}$ Alfons Renaldo Tampenawas, Erna Ngala, and Maria Taliwuna, "Teladan Tuhan Yesus Menurut Injil Matius Dan Implementasinya Bagi Guru Kristen Masa Kini," EDULEAD: Journal of Christian Education and Leadership 1, no. 2 (December 10, 2020): 214-231, http://stak-pesat.ac.id/ejournal/index.php/edulead/article/view/44.

${ }^{11}$ Sudiria Hura and Marde Christian Stenly Mawikere, "KAJIAN BIBLIKA MENGENAI PENDIDIKAN ANAK DAN HAKIKAT PENDIDIKAN ANAK USIA DINI," EDULEAD: Journal of Christian Education and Leadership 1, no. 1 (2020): 15-33.

12 Adelaide F. Heath, Strategi Membimbing Anak Hidup Dalam Kristus.

${ }^{13}$ Ibid.

${ }^{14}$ Nani Pratiwi and Nola Pritanova, "Pengaruh Literasi Digital Terhadap Psikologis Anak Dan Remaja," Semantik 6, no. 1 (2017): 11-24. 


\section{METODE PENELITIAN}

Metode penelitian dalam penulisan karya ilmiah ini yaitu menggunakan metode penelitian kualitatif. Di mana pada penelitian ini yang menjadi instrument penelitian adalah wawancara. Selanjutnya, informan dalam penelitian ini adalah orang yang akan memberi sumber data atau orang yang akan memberikan informasi mengenai penelitian yang dilakukan. Dengan demikian informan atau orang kunci yang di maksud dalam penelitian ini adalah anak-anak Future Center Sion Tridamarsari usia 13-16 tahun yang beragama Kristen. Jumlah informan adalah 9 anak yang terdiri dari 6 laki-laki dan 3 perempuan.

\section{HASIL DAN PEMBAHASAN}

\section{Penginjilan}

Kata penginjilan memiliki arti kata dasar "Injil" yang berasal dari bahasa Yunani "Evanggelion" yang berarti "kabar gembira" atau "kabar baik" ${ }^{15}$. Hal serupa pun dikemukakan oleh Makmur Halim, yang mengatakan bahwa penginjilan atau evangelism, barasal dari bahasa Yunani yaitu "Evangelion" yang berarti kabar baik. Kabar baik yang dimaksud adalah Injil ${ }^{16}$.

Penginjilan atau pemberitaan Injil merupakan kata yang tidak asing lagi bagi orangorang Kristen. Istilah penginjilan merupakan bagian yang tidak terpisahkan dari Kekristenan ${ }^{17}$. Penginjilan merupakan suatu perintah yang diharuskan untuk dikerjakan dalam kehidupan manusia. Penginjilan dilakukan bagi orang yang telah menerima dan percaya kepada Yesus sebagai Tuhan dan Juruselamat. Namun setiap orang percaya harus mengetahui apa maksud dan tujuan dari penginjilan. Sebagai orang percaya dapat mengacu pada Mat. 28:18-20 yang menjadi dasar penginjilan. Isi Mat. 28:18-20 menyatakan: Yesus mendekati mereka dan berkata:"Kepada-Ku telah diberikan segala kuasa di Sorga dan di bumi. Karena itu pergilah, jadikanlah semua bangsa murid-Ku dan baptislah mereka dalam nama Bapa dan Anak dan Roh Kudus, dan ajarlah mereka melakukan segala sesuatu yang telah Kuperintahkan kepadamu. Dan ketahuilah, Aku menyertai kamu senantiasa sampai kepada akhir zaman." Hal ini menunjukkan bahwa penginjilan merupakan perintah yang mutlak diberikan oleh

\footnotetext{
15 Timotius Sukarman, Gereja Yang Bertumbuh Dan Berkembang (Yogyakarta: Andi, 2012), 34.

${ }^{16}$ Makmur Halim, Model-Model Penginjilan Yesus: Suatu Penerapan Masa Kini (Penerbit Gandum Mas, 2003), 25.

${ }^{17}$ Peter S. Wong, Injil Yesus Kristus (Sebuah Pengantar Teologi Injili) (Jakarta: Yayasan Kartidaya, 2011), 3 .
} 
Yesus Kristus dan harus dilakukan oleh setiap orang percaya. Dalam penginjilan, yang menjadi inti sari adalah Injil. Injil adalah Kristus telah mati bagi dosa-dosa manusia dan bangkit dari antara orang mati. Kematian Yesus membayar upah dosa manusia. Bahwa Kristus dikuburkan membuktikan bahwa Yesus memang mati, dan kebangkitan Yesus membuktikan bahwa pengorbanan darah Yesus berkenan kepada Allah dan memuaskan amarah Allah terhadap manusia berdosa ${ }^{18}$.

\section{Keyakinan Keselamatan}

Dalam kehidupan kekristenan, seseorang yang memiliki keyakinan keselamatan adalah seseorang yang menyadari bahwa Allah pemberi atau memberi keselamatan melalui pengorbanan Yesus Kristus di kayu salib. Keyakinan keselamatan tersebut bagian dari dasar Injil. Dengan keyakinan keselamatan yang dimiliki, maka kesadaran akan hidup untuk Allah dan sesama akan menjadi lebih baik (Ef. 2:10).

Keselamatan satu-satunya cara yang dipilih Allah agar manusia kembali bersekutu dengan Allah. Orang tidak mungkin dapat mencapai keselamatan di luar Yesus Kristus sekalipun banyak pandangan yang mengajarkan bahwa ada cara lain yang dapat diperoleh agar seseorang bisa mendapatkan keselamatan tanpa harus melalui Yesus Kristus. Bagi mereka Yesus Kristus adalah salah satu jalan keselamatan dan bukan satu-satunya jalan keselamatan. ${ }^{19}$ Oleh karena itu sebagai seorang Kristen harus memiliki pandangan yang benar dan keyakinan yang benar dengan meyakini bahwa Yesus adalah satu-satunya Tuhan dan Juruselamat.

Proses penginjilan pada anak harus dilakukan oleh para tutor. Khusunya pada anakanak Kristen. Hal tersebut bertujuan agar anak-anak yang dilayani dalam Future Center Sion Tridamarsari yakin menerima anugerah hidup kekal dan memiliki iman yang teguh dalam Yesus Kristus serta tutor mampu memberikan sebuah pemahaman yang baik tentang Yesus Kristus.

Berdasarkan hasil wawancara guna untuk mengetahui penginjilan pada anak, maka berikut merupakan hasil pengumpulan data melalui wawancara bersama para tutor yang mendampingi anak-anak Future Center Sion Tridamarsari usia 13-16 tahun atau kelas NDP.

18 Santosa Santosa and Guntur Firman Aprianto, "Implementasi Penginjilan Dan Pemuridan Dalam Pengembangan Karakter Jujur Anak Usia 9-10 Tahun,” JURNAL TEOLOGI GRACIA DEO 2, no. 2 (2020): 94-108.

19 Federans Randa, "KARYA KESELAMATAN ALLAH DALAM YESUS KRISTUS SEBAGAI JAMINAN MANUSIA BEBAS DARI HUKUMAN KEKAL ALLAH," LOGON ZOES: Jurnal Teologi, Sosial dan Budaya 3, no. 1 (2020): 35-62. 
HARVESTER: Jurnal Teologi dan Kepemimpinan Kristen, Vol 5, No 2, (Desember 2020)

EHN merupakan koordinator dan SQA, EHN mendampingi 3 anak Kristen pada kelas NDP. Menurut EHN, hal terpenting dalam menyampaikan injil pada anak-anak yaitu bagaimana cara tutor untuk mengenalkan Yesus dan mengetahui siapa itu Tuhan Yesus. Ketika anak-anak sudah mengetahui dan mengenal, maka dengan mudah untuk membawa anak-anak Kristen yang dilayani memercayai Yesus Kristus sebagai Tuhan dan Juruselamat secara pribadi. EHN melanjutkan bahwa walaupun dalam kenyataannya, anak-anak Kristen yang dilayani dalam kelas NDP, secara khusus sudah mengetahui Yesus, namun di usia mereka saat ini anak NDP masih perlu ditolong untuk bertumbuh pada konsep kepercayaan kepada Tuhan Yesus. ${ }^{20}$

DMK merupakan tutor yang juga menangani 3 anak yang beragama Kristen dalam kelompok bimbingan Future Center NDP. Menurut DMK menginjili anak-anak sudah terstruktur melalui program Unleashed ${ }^{21}$, karena Alkitab menjadi dasar dari membimbing dan mendampingi anak NDP. Penginjilan yang dilakukan oleh DMK belum menggunakan metode EE (Evangelism Explotion). DMK melanjutkan bahwa penginjilan yang dilakukan pada anak-anak yang dilayani, secara tidak langsung adalah menggunakan video-video ${ }^{22}$ yang berlandaskan ayat-ayat Alkitab DMK menjelaskan bahwa metode yang digunakan untuk meneguhkan keyakinan keselamatan anak NDP menggunakan video-video pembelajaran mengenai tokoh-tokoh Alkitab yang akan menuntun ke arah pertumbuhan karakter ketika anak merefleksikan isi video, kemudian dilakukan sharing bersama. ${ }^{23}$

MJN adalah tutor yang juga menangani anak NDP. Dalam kelompok MJN, terdapat 4 anak yang beragama Kristen. Menurut MJN, menginjili tidak langsung mengatakan Yesus, atau mengajak seseorang untuk langsung percaya Yesus. Kemudian MJN melanjutkan bahwa, menginjili anak-anak Kristen agar tetap teguh dalam Yesus adalah dengan cara membawa Tuhan selalu dalam kehidupan sehari-hari, bahkan melihat pengorbanan Tuhan yang telah diberikan bagi umat manusia yang berdosa melalui diskusi, sharing bahkan nasihat. Selain itu MJN menjelaskan bahwa, menginjili anak pun dapat dilakukan dengan memberikan tugas-tugas yang ada dalam kurikulum Unleashed. MJN menyatakan bahwa

\footnotetext{
${ }^{20}$ Hasil Wawancara dengan EHN, pada tanggal 9 Juli 2020, pukul 16:13 WIB

${ }^{21}$ Unleashed merupakan program dari lembaga LAD (Leadership As Discipleship). Penjelasan tersebut dapat dilihat dalam Kurikulum Future Center Nurture Dreams Program (-:2018), hal.1

22 Video yang digunakan merupakan video yang telah disediakan oleh Unleashed. Karena anak Future Center NDP menggunakan kurikulum Unleashed dalam pembinaannya. Video tersebut menceritakan karakter dari tokoh-tokoh Alkitab. Salah satu judul video yang digunakan dalam pembinaan anak yaitu "Sikap dan Jalan Hidup yang Mulia (Ayub 42:10). (Hasil Wawancara melalui Chatting Via Whatsapp dengan DMK, pada tanggal 29 Juli 2020, pukul 11:53 WIB)

${ }^{23}$ Hasil Wawancara dengan DMK, pada tanggal 10 Juli 2020, pukul 13:43 WIB
} Copyright@ 2020; HARVESTER; e-ISSN 2685-0834, p-ISSN 2302-9498 | 127 
penginjilan kepada anak-anak NDP yang Kristen dilakukan secara terbuka, seperti mengajak anak untuk terlibat dalam pelayanan di gereja. ${ }^{24} \mathrm{Jika}$ berdasarkan teori-teori yang dijelaskan mengenai penginjilan maka bagian yang dilakukan oleh MJN dengan cara mengajak anak untuk terlibat dalam pelayanan di gereja adalah bukan suatu penginjilan, melainkan melibatkan anak dalam suatu pelayanan gereja atau memuridkan anak.

Berkaitan dengan hasil penelitian melalui wawancara yang dilakukan pada ketiga tutor Future Center Sion Tridamarsari usia 13-16 tahun atau NDP di atas, maka ketiga tutor yang mendampingi anak-anak Kristen, jika melalui kurikulum Unleashed dapat disimpulkan bahwa masing-masing tutor belum menginjili. Proyek yang dilakukan para tutor adalah menolong anak tumbuh memiliki karakter seperti Kristus.

\section{Percaya Pada Yesus}

Percaya pada Yesus merupakan memiliki suatu pengakuan yang tepat untuk menerima anugerah hidup kekal dari Allah. Berikut merupakan hasil wawancara yang dilakukan pada anak Future Center Sion Tridamarsari usia 13-16 tahun atau NDP sebagai Informan dalam penelitian.

Tabel Informan Future Center Sion Tridamarsari

Yang Percaya pada Yesus

\begin{tabular}{|l|l|l|}
\hline Informan & Percaya & Alasan Anak \\
\hline MF & Percaya & Karena Yesus telah rela mati untuk menebus dosa. \\
\hline JRWA & Percaya & $\begin{array}{l}\text { Yesus adalah Juruselamat. Namun YC masih ragu } \\
\text { mengenai keselamatannya karena perbuatan yang } \\
\text { kurang baik. }\end{array}$ \\
\hline ARYP & Percaya & $\begin{array}{l}\text { Yesus telah menebus dosa. Yakin diselamatkan. } \\
\text { diselamatkan. menebus dosa-dosanya. Yakin }\end{array}$ \\
\hline GN & Percaya & $\begin{array}{l}\text { Yesus telah menebus dosa-dosanya. Yakin } \\
\text { diselamatkan karena Tuhan memperhitungkan } \\
\text { pelayanannya. AN yakin }\end{array}$ \\
\hline AN & Percaya & $\begin{array}{l}\text { Tuhan yang memberikan kehidupan. AN } \\
\text { diselamatkan karena Tuhan memberi jalan keluar. }\end{array}$ \\
\hline TP & Percaya & $\begin{array}{l}\text { Belum mengetahui alasan memercayai Yesus. Namun } \\
\text { yakin bahwa akan diselamatkan oleh Yesus. }\end{array}$ \\
\hline AS & Percaya & $\begin{array}{l}\text { Tuhan Yesus sanggup melindungi kehidupannya dan } \\
\text { yakin diselamatkan karena Tuhan melindungi. }\end{array}$ \\
\hline YSS & Percaya & \begin{tabular}{l} 
Yesus Juruselamat. \\
\hline
\end{tabular}
\end{tabular}

${ }^{24}$ Hasil Wawancara dengan MJN, pada tanggal 11 Juli 2020, pukul 12:23 WIB 
HARVESTER: Jurnal Teologi dan Kepemimpinan Kristen, Vol 5, No 2, (Desember 2020)

Berdasarkan tabel di atas, dari 9 informan yang diwawancarai maka dapat dilihat bahwa semua informan menyatakan percaya pada Yesus. Dari data di atas tersebut dapat dilihat bahwa YS menjelaskan alasan percaya karena Yesus adalah Juruselamat. Berbeda dengan YC, walaupun menjelaskan percaya karena Yesus adalah Juruselamatnya namun YC masih ragu dengan keselamatannya. Sedangkan JR, ARYP, dan GN menjawab percaya karena Yesus telah menebus dosanya, AS percaya karena Yesus sanggup melindungi, AN percaya karena Tuhan memberi jalan keluar. Namun TP belum mengetahui alasan percaya pada Yesus. Dengan demikian, AS, AN dan TP perlu dibimbing untuk memahami pribadi Yesus dalam konsep penginjilan.

\section{Yesus Jaminan Keselamatan}

Yesus jaminan keselamatan merupakan suatu deklarasi yang telah dituliskan dalam Injil Yohanes 14:6, bahwa Yesus adalah jalan dan kebenaran dan hidup. Dengan demikian dapat disimpulkan bahwa Yesus jaminan keselamatan setiap orang percaya (Yoh. 3:16).

Berikut merupakan hasil wawancara yang dilakukan pada anak Future Center Sion Tridamarsari usia 13-16 tahun sebagai Informan dalam penelitian.

Tabel Informan Future Center Sion Tridamarsari

Yesus Jaminan Keselamatan

\begin{tabular}{|c|c|l|l|}
\hline \multirow{2}{*}{ Narasumber } & \multicolumn{3}{|c|}{ Respon Anak } \\
\cline { 2 - 4 } & $\begin{array}{l}\text { Keyakinan } \\
\text { Keselamatan }\end{array}$ & Yemahaman & Cara \\
\hline MF & Yakin & $\begin{array}{l}\text { Yesus sudah mati } \\
\text { untuk ku }\end{array}$ & Percaya saja \\
\hline YC & Ylkitab dalam ayat & $\begin{array}{l}\text { Berbuat baik dan } \\
\text { percaya pada Tuhan } \\
\text { Yesus }\end{array}$ \\
\hline JRWA & Yakin & Khotbah dan Alkitab & $\begin{array}{l}\text { Berdoa, baca Alkitab, } \\
\text { memuji Tuhan. }\end{array}$ \\
\hline ARYP & Yakin & $\begin{array}{l}\text { Baca firman, ke gereja } \\
\text { dan doa. }\end{array}$ & $\begin{array}{l}\text { Percaya, karena sudah } \\
\text { di tebus. } \\
\text { dalam Alkitab dan ikut } \\
\text { perintah Allah. }\end{array}$ \\
\hline GN & Ragu-ragu & Kesaksian orang lain & $\begin{array}{l}\text { Percaya pada Tuhan } \\
\text { Yesus. }\end{array}$ \\
\hline AN & Yakin & Diajarkan di Alkitab & $\begin{array}{l}\text { Berdoa dan melakukan } \\
\text { hal-hal positif. }\end{array}$ \\
\hline TP & Yakin & Kehidupan sehari-hari & $\begin{array}{l}\text { Berdoa dan } \\
\text { beribadah. }\end{array}$ \\
\hline AS & & \multicolumn{2}{|c|}{} \\
\hline
\end{tabular}




\begin{tabular}{|c|l|l|l|}
\hline YSS & Yakin & Ajaran Alkitab & $\begin{array}{l}\text { Taat dan percaya pada } \\
\text { Tuhan Yesus. }\end{array}$ \\
\hline
\end{tabular}

Berdasarkan tabel di atas, dari 9 informan yang diwawancarai, terdapat 8 anak yang yakin diselamatkan namun 1 anak yang ragu-ragu, walaupun percaya pada Yesus. Kemudian jika dilihat pada tabel 4.3.1, bahwa YC pun masih ragu dengan keselamatannya. Jika dikelompokkan maka terdapat 2 anak yang masih ragu-ragu.

Dilihat secara spesifik di kolom cara pada tabel 4.3.1, terdapat 4 anak yang yakin diselamatkan karena pecaya pada Yesus. Namun 6 anak yakin diselamatkan karena mengikuti kegiatan kerohanian dan 3 anak ragu-ragu diselamatkan walaupun percaya pada Yesus. Dengan demikian dapat dipahami melalui hasil wawancara bersama tutor, bahwa para tutor tidak melakukan penginjilan pada anak-anak Future Center Sion Tridamarsari usia 13-16 tahun. Terlihat dari penjelasan para turor di atas, menginjili anak dengan membawa mereka ke gereja dan melakukan kegiatan kerohanian.

\section{Berani Bersaksi}

Berani bersaksi merupakan menceritakan karya Allah dalam hidup dengan kuasa Roh Kudus pada orang lain, baik melalui kehidupan sehari-hari, di gereja dan menceritakan keselamatan dalam Yesus Kristus. Berikut merupakan tabel hasil wawancara yang dilakukan pada anak-anak Future Center Sion Tridamarsari usia 13-16 tahun atau NDP sebagai Informan mengenai bersaksi sesuai dengan indikator penelitian.

Tabel Informan Future Center Sion Tridamarsari yang Berani Beraksi

\begin{tabular}{|c|c|c|c|l|}
\hline \multirow{2}{*}{ Narasumber } & \multicolumn{2}{|c|}{ Bersaksi } & \multicolumn{1}{|c|}{ Respon } \\
\hline & Pernah & Belum & Metode & \multicolumn{1}{|c|}{} \\
\hline MF & Pernah & & Bercerita & Ada yang menangis. \\
\hline YC & Pernah & & Bercerita & $\begin{array}{l}\text { Diskusi bersama teman } \\
\text { yang beda agama }\end{array}$ \\
\hline ARYP & Pernah & & Bercerita & $\begin{array}{l}\text { Mau masuk Kristen saat } \\
\text { SMA. }\end{array}$ \\
\hline GN & Pernah & & Bercerita & $\begin{array}{l}\text { Belajar mahami } \\
\text { kehidupan Kristen. }\end{array}$ \\
\hline AN & Pernah & & Sharing & $\begin{array}{l}\text { Ada yang percaya dan tidak } \\
\text { percaya. } \\
-\end{array}$ \\
\hline TP & & Belum & & \multicolumn{2}{|l}{} \\
\hline
\end{tabular}


HARVESTER: Jurnal Teologi dan Kepemimpinan Kristen, Vol 5, No 2, (Desember 2020)

\begin{tabular}{|c|c|c|c|l|}
\hline AS & Pernah & & Bercerita & $\begin{array}{l}\text { Mengakui keberadaan } \\
\text { Tuhan. }\end{array}$ \\
\hline YSS & Pernah & & Bercerita & Sudah lupa \\
\hline
\end{tabular}

Berdasarkan tabel di atas, dari 9 informan yang diwawancarai, maka dapat dilihat bahwa 8 anak pernah bersaksi dan 1 anak belum pernah bersaksi. Metode yang digunakan informan dalam menceritakan Yesus yaitu melalui bercerita atau sharing. Dapat dipahami bahwa 8 anak yang pernah menceritakan Yesus pada orang lain bahkan pada orang yang berbeda agama, jika dilihat dari respon maka anak mempunyai keberanian dan mengimani Yesus sebagai Tuhan dalam hidupnya.

\section{Mendoakan Orang Lain}

Berdoa merupakan fondasi bagi kesejahteraan jiwa dan mendoakan orang lain merupakan suatu pengaharapan pada Tuhan Yesus untuk orang lain. Berikut merupakan tabel hasil wawancara yang dilakukan pada anak-anak Future Center Sion Tridamarsari usia 13-16 tahun atau NDP sebagai Informan mengenai bersaksi sesuai dengan indikator penelitian.

Tabel Informan Future Center Sion Tridamarsari yang Mendoakan Orang Lain

\begin{tabular}{|c|c|l|}
\hline Narasumber & $\begin{array}{c}\text { Berdoa dan mendoakan } \\
\text { Orang Lain }\end{array}$ & Alasan \\
\hline MF & Pernah & Belum tahu. \\
\hline YC & Pernah & $\begin{array}{l}\text { Karena doa itu napas hidup orang } \\
\text { Kristen dan sudah berbuat baik. }\end{array}$ \\
\hline JRWA & Pernah & Memberkati orang lain. \\
\hline ARYP & Pernah & Memberkati orang lain. \\
\hline GN & Pernah & $\begin{array}{l}\text { Agar keinginan orang lain } \\
\text { terkabulkan. }\end{array}$ \\
\hline AN & Pernah & $\begin{array}{l}\text { Dengan mendoakan menunjukkan } \\
\text { kasih yang tidak kelihatan. }\end{array}$ \\
\hline TP & Pernah & $\begin{array}{l}\text { Melalui doa bisa membalas kejahatan } \\
\text { dengan kebaikan. }\end{array}$ \\
\hline AS & Pernah & $\begin{array}{l}\text { Jika orang lain sakit harus didoakan } \\
\text { agar sembuh. }\end{array}$ \\
\hline YSS & Pernah & Belum tahu. \\
\hline
\end{tabular}

Berdasarkan tabel di atas, dari 9 informan yang diwawancarai, dapat dilihat bahwa semua informan pernah berdoa dan mendoakan orang lain. Dari setiap alasan yang 
disampaikan, dapat dilihat bahwa MF dan YS belum mengetahui mengapa harus berdoa. Dapat dipahami bahwa belum adanya pembimbingan pada anak tujuan berdoa oleh para tutor.

Hasil penelitian mengenai penginjilan sebagai upaya meneguhkan keyakinan keselamatan anak Future Center Sion Tridamarsari Purwosari, jika para tutor menggunakan strategi Weekly Meeting yang melakukan kegiatan-kegiatan seperti; menonton video-video pembelajran mengenai tokoh-tokoh Alkitab yang berlandaskan ayat Alkitab, refleksi video, nasihat, sharing, memberikan proyek-proyek, membawa anak ke gereja dan melakukan kegiatan kerohanian, dapat dipahami bukan merupakan bagian dari suatu bentuk penginjilan.

Hal di atas tersebut terlihat dari hasil wawancara bersama 9 informan dalam penelitian ini, bahwa pada indikator percaya pada Yesus secara keseluruhan anak menjawab percaya. Alasan tersebut dikarenakan semua anak beragama Kristen yang secara otomatis percaya pada Yesus. Namun jika melihat alasannya, ada 5 anak yang menjelaskan secara relevan mengapa percaya Yesus, seperti MF, JRWA, ARYP, GN dan YSS. Sedangkan anak lainnya ada yang ragu yaitu YC, bahkan TP tidak tahu alasan mengapa percaya pada Yesus, dan 2 anak lainnya yaitu AS dan AN percaya Yesus bertujuan untuk menolong kehidupan seharihari.

Indikator lainnya adalah Yesus jaminan keselamatan. Dari 9 informan menunjukkan hasil bahwa 8 yakin diselamatkan namun 1 ragu-ragu. Namun pemahaman atau alasan yang disampaikan oleh anak, terdapat 6 anak-anak yang yakin diselamatkan dalam Yesus. Seperti JRWA, ARYP, GN, TP, AS, dan YSS namun memberikan alasan yang tidak tepat dalam konsep keselamatan. Karena alasan mereka mengacu pada kegiatan kerohanian yang dilakukan. Namun MF dan AN memberikan yakin diselamatkan karena percaya pada Tuhan Yesus. Jika pada indikator bersaksi, terdapat 8 informan yang pernah bersaksi dan 1 informan lainnya belum pernah bersaksi. Kemudian indikator mendoakan orang lain, semua anak pernah mendoakan orang lain, karena bagian seperti mendoakan orang lain sering ditanamkan pada anak-anak Future Center usia 13-16 tahun.

Berdasarkan hasil wawancara pada indikator percaya pada Yesus dan Yesus jaminan keselamatan bahkan hasil wawancara bersama para tutor, maka penjelasan di atas dapat memberikan bukti bahwa para tutor belum menginjili anak-anak Kristen yang dilayani pada Future Center Sion Tridamarsari usia 13-16 tahun. Karena sebagian besar anak-anak belum mengetahui alasan jelas mengenai kenapa harus percaya pada Yesus dan Yesus jaminan keselamatan bagi setiap orang yang percaya. 
HARVESTER: Jurnal Teologi dan Kepemimpinan Kristen, Vol 5, No 2, (Desember 2020)

\section{KESIMPULAN}

Berdasarkan hasil penelitian, dapat disimpulkan bahwa para tutor yang melayani di Future Center Sion Tridamarsari lebih fokus pada pembinaan karakter melalui kurikulum Unleashed, yang memberikan kontribusi untuk menolong anak bertumbuh dan memiliki karakter yang baik serta mengembangkan potensi yang ada pada diri anak. Kegiatan tutor dan anak yang dilakukan dalam pertemuan Weekly Meeting terlihat belum maksimal dalam penginjilan pada anak-anak Kristen yang dilayani.

Dari sembilan informan dalam penelitian ini yaitu YSS, MF, TP, AN, YC, ARYP, AS, JRWA, dan GN merupakan anak-anak yang percaya pada Yesus, yakin bahwa Yesus jaminan keselamatan, sebagian dari informan pernah bersaksi dan pernah berdoa bahkan mendoakan orang lain. Jika difokuskan pada keyakinan keselamatan yang teguh pada Yesus Kristus maka sebagian dari informan penelitian belum mengetahui alasan dasar yakin diselamatkan dalam Yesus.

Melihat penginjilan belum dimaksimalkan dalam pelayanan yang dikerjakan maka dapat disimpulkan bahwa para tutor belum memberikan dampak yang mampu meneguhkan keyakinan keselamatan dalam Yesus Kristus pada anak Kristen yang dilayani dalam Future Center Sion Tridamarsari usia 13-16 tahun.

\section{DAFTAR PUSTAKA}

Adelaide F. Heath. Strategi Membimbing Anak Hidup Dalam Kristus. Bandung: Kalam AlHayat, 2013.

Fredy, Fredy. “Ajaran Tentang Keselamatan Dalam Kitab Injil Yohanes” (2018).

Halim, Makmur. Model-Model Penginjilan Yesus: Suatu Penerapan Masa Kini. Penerbit Gandum Mas, 2003.

Hura, Sudiria, and Marde Christian Stenly Mawikere. "KAJIAN BIBLIKA MENGENAI PENDIDIKAN ANAK DAN HAKIKAT PENDIDIKAN ANAK USIA DINI.” EDULEAD: Journal of Christian Education and Leadership 1, no. 1 (2020): 15-33.

Keriapy, Frets. "Pendidikan Kristiani Transformatif Berbasis Multikultural Dalam Konteks Indonesia." REGULA FIDEI: Jurnal Pendidikan Agama Kristen 5, no. 2 (2020): 82-93.

Peter S. Wong. Injil Yesus Kristus (Sebuah Pengantar Teologi Injili). Jakarta: Yayasan Kartidaya, 2011.

Pratiwi, Nani, and Nola Pritanova. "Pengaruh Literasi Digital Terhadap Psikologis Anak Dan Remaja." Semantik 6, no. 1 (2017): 11-24. 
Randa, Federans. "KARYA KESELAMATAN ALLAH DALAM YESUS KRISTUS SEBAGAI JAMINAN MANUSIA BEBAS DARI HUKUMAN KEKAL ALLAH.” LOGON ZOES: Jurnal Teologi, Sosial dan Budaya 3, no. 1 (2020): 35-62.

Romini, Romini, and Ida Destariana Harefa. "MANFAAT PENGGUNAAN ALKITAB BERGAMBAR TERHADAP PERKEMBANGAN KEROHANIAN ANAK FUTURE CENTER USIA 7-9 TAHUN DI BULUH AWAR." EDULEAD: Journal of Christian Education and Leadership 1, no. 1 (2020): 1-14.

Sam Doherty. Mengapa Menginjili Anak-Anak. Indonesia, 2002.

Santosa, Santosa, and Guntur Firman Aprianto. "Implementasi Penginjilan Dan Pemuridan Dalam Pengembangan Karakter Jujur Anak Usia 9-10 Tahun.” JURNAL TEOLOGI GRACIA DEO 2, no. 2 (2020): 94-108.

Stephanus, Djuwansah Suhendro P. "Mengajarkan Penginjilan Sebagai Gaya Hidup Orang Percaya.” REDOMINATE: Jurnal Teologi dan Pendidikan Kristiani 1, no. 1 (2019): $12-22$.

Sugiyono. Metode Penelitian Pendidikan (Pendekatan Kuantitatif, Kualitatif Dan R\&D). Bandung: Alfabeta, 2016.

Tampenawas, Alfons Renaldo, Erna Ngala, and Maria Taliwuna. “Teladan Tuhan Yesus Menurut Injil Matius Dan Implementasinya Bagi Guru Kristen Masa Kini.” EDULEAD: Journal of Christian Education and Leadership 1, no. 2 (December 10, 2020): 214-231. http://stak-pesat.ac.id/e-journal/index.php/edulead/article/view/44.

Timotius Sukarman. Gereja Yang Bertumbuh Dan Berkembang. Yogyakarta: Andi, 2012. Y. Tomatala. Penginjilan Masa Kini Jilid 2. Malang: Gandum Mas, 2004. 